\title{
WORKING EFFECTIVELY WITH PSYCHOLOGICALLY IMPAIRED FACULTY
}

\author{
Carolyn B. Oxenford, Marymount University \\ Sally L. Kublenschmidt, Western Kentucky University
}

More than one-fourth of all residents of the United States experience mental health disorders in any given year. Evidence suggests that faculty are more likely to suffer from psychological impairment than the general population. This chapter reviews evidence on faculty stress and impairment and helps faculty developers recognize signs that mental bealth issues may be affecting faculty performance. It also will belp faculty developers understand legal issues in relation to faculty impairment and belp them work effectively with colleagues who are coping with psychological impairments.

Based on the most recent National Comorbidity Survey Replication (Lacey, 2005), more than one-fourth of U.S. adults reported symptoms severe enough to constitute a diagnosable mental disorder during a given twelve-month period. Over half of those disorders were classified as serious or moderate, and thus likely to impair the individual's effective functioning. The same survey estimated that approximately half of Americans will experience symptoms of a diagnosable mental disorder over their lifetime. In a survey of faculty, Schwebel (2009) found that 20 to 25 percent of respondents experienced some form of mental illness at any given time.

Psychological distress appeared to be more common in academic staff than in the general population in an Australian study (Winefield, 2000). A sample of British academic staff self-reported higher levels of burnout, depression, and anxiety than the general population did (Kinman, 2001). Slightly over half of those assessed in this study were found to need 
mental health intervention. A recent Chronicle of Higher Education report indicated that 12 to 13 percent of U.S. college employees, including staff, who went on disability did so for mental health reasons, compared to 7 percent in other professions (Ruark, 2010).

Because this research suggests that faculty members are at least slightly more likely than the general population to experience psychological distress, faculty developers should expect to encounter colleagues whose mental health is having a negative impact on their performance. While many aspects of working with psychologically impaired colleagues are similar to other consultations, some unique situations need to be recognized and handled differently.

\section{Stress and the Professorial Personality}

Although university teaching has often been viewed as a low-stress job, recent research suggests increasing stress levels over the past three decades (Gillespie, Walsh, Winefield, Dua, \& Stough, 2001). Studies of Australian academic staff suggest a marked increase in stress over a five-year period and found that academic staff experienced more stress and negative health effects due to stress than did nonacademic staff (Gillespie et al., 2001). Academic staff involved in both teaching and research experienced higher levels of stress than those who were engaged in only one of those functions (Winefield \& Jarrett, 2001). Kinman (2001) found cognitive impairments, increased behavioral problems such as absenteeism and substance abuse, and physical and psychological symptoms associated with higher levels of stress in the United Kingdom. In the United States, Hogan, Carlson, and Dua (2002) found that stress correlated positively with behavioral, cognitive, and physiological symptoms and with negative emotionality.

A number of common sources of stress in academia were identified in these studies and others (Abouserie, 1996; Blix, Cruise, Mitchell, \& Blix, 1994; Dua, 1994; Winefield et al., 2003):

- Increasing workloads and higher accountability demands

- Ambiguous tenure and promotion standards

- Increased competition for grants, publications, and positions

- High-stakes peer assessments and public criticism

- Unsupportive administrators and reduced autonomy

- Fiscal pressures, including reduced funding, salary freezes, furloughs, and delayed retirement 
- For some, an expectation of independent work and sole authorship

- Increased research and publication pressures

- Increased work-home conflict due to work pressures

Some research suggests that individuals attracted to academic careers have characteristics that may exacerbate the effects of environmental stressors. In particular, faculty tend to be highly intelligent and prone to maladaptive perfectionism, defined as "punishing and unattainable standards that reflect an inadequate sense of self and that can lead to unyielding self-criticism and an inability to experience pleasure through normal accomplishments" (Dunn, Whelton, \& Sharpe, 2006, p. 511).

Most studies have found stress levels to be highest in untenured and female faculty (Blix et al., 1994; Hogan et al., 2002; Winefield \& Jarrett, 2001). No gender effect was found in a Welsh university sample (Abouserie, 1996); however, the lack of sample detail makes comparisons difficult. Machell (1988) described a debilitating sequence he called professional melancholia. This progressive deterioration of self-esteem and emotional health begins when young professors with unrealistic expectations of perfection and approval discover that they are no longer star students. Professional competition and inevitable rejections lead to increasing levels of hurt, resentment, and frustration. The faculty member begins to build a self-protective wall that leads to further loss of motivation, decreased scholarly interest, and lowered self-esteem. At its most extreme, professional melancholia can result in contempt for students and colleagues, deep alienation, elitism, and arrogance.

High continuing stress levels are associated with a variety of psychological symptoms in academic staff, including withdrawal, cynicism, burnout, dissatisfaction, and health complaints (Dua, 1994; Hogan et al., 2002; Winefield et al., 2003). Stress also can exacerbate underlying mental health disorders. Individuals with significant mental health issues usually show lowered creativity, problem-solving, decision-making, and concentration skills, and they are less productive and less accessible to students and colleagues (Boston University, n.d.).

\section{Recognizing Mental Health Issues}

A mental disorder is an extreme version of common behaviors. These behaviors reach the level of disorder when they actively interfere with a person's effectiveness or happiness (American Psychiatric Association, 1994). Professor A forgets to return papers but eventually does so and grades them appropriately. Students are annoyed but not harmed. 
Professor B loses papers repeatedly and cannot recall conversations with students or colleagues. Grades are missing or seem randomly assigned. Students are upset, and departmental work is undone.

The boundary between eccentricity and disorder depends on environmental norms. Some university environments tolerate highly eccentric behavior. Faculty with mental health issues can continue to function, but their problems can become fairly severe before tolerance is exhausted. Other institutions or departments may tolerate very little eccentricity or view differences as weakness, leading to a loss of resources or respect for the faculty member, which has the effect of encouraging faculty to hide their problems. Due to their intelligence and creativity, faculty members can be good at adapting to their environments. Given time and support, they may resolve their own issues. They can also be good at hiding their problems and therefore not get the help they need.

In order to help psychologically impaired faculty, it is not necessary for a faculty developer to become a clinician, but it helps to be aware of behavior patterns that might signal mental health issues. The sections that follow offer a broad overview of behavioral signs for the most frequently diagnosed clusters of mental health disorders (American Psychiatric Association, 1994; Lacey, 2005). Individuals without mental health problems also display these behaviors, and at some level, most of them are reasonable responses to specific situations. Many of us find echoes of ourselves in the following list, but it is the particular combination of symptoms, their severity, and disrupted functioning that creates cause for concern. A faculty member showing many of the signs for one or more of these disorders should alert the faculty developer that referral to a mental health professional may be needed.

\section{Anxiety Disorders}

These include phobias, panic disorder, obsessive-compulsive disorder, and posttraumatic stress disorder (PTSD). Common symptoms are excessive worrying, repetitive behaviors, frequent illness, obvious tension and jumpiness, reluctance to change routines, and avoidance of certain situations. Rigid, moralistic, or perfectionist attitudes are common in some of these disorders. In the classroom, faculty may display excessive nervousness, overly detailed preparation that interferes with performance, a focus on perfection in their own and students' work, rigidity about class rules and routines, avoidance of activities (such as public speaking, night teaching, or participating in new initiatives), overreaction to plagiarism, or difficulty managing student problems calmly. High levels of structure 
and predictability help these individuals function, but change may trigger deterioration.

\section{Mood Disorders}

Mood disorders include major depression, dysthymia (mild, chronic depression), bipolar disorder, cyclothymia (persistent pattern of periods of elevated, expansive, or irritable mood alternating with periods of dysthymia), and seasonal affective disorder. Depressed individuals may show flat or sad affect, low energy, fatigue, concentration problems, hopelessness (sometimes including suicidal thoughts), altered eating or sleeping patterns, and loss of interest in pleasurable activities. For those who are bipolar, periods of depression alternate with periods of agitation, high energy, inflated self-esteem, distractibility, unrestrained behavior, and racing thoughts. Moods may swing rapidly or more slowly and vary in their extremity. At the most extreme ends, mood disorders may appear psychotic. Signs of faculty depression might include dismissing class early, missing meetings or classes, and failure to make progress on scholarship. Lack of concentration and organization is also likely. Manic individuals may dominate conversations excessively and make unrealistic promises. Creating grandiose plans that are never completed also characterizes individuals with manic disorders. Mild depression and mania may not meet full diagnostic criteria but are still disruptive. Depression also can accompany events such as the loss of a loved one or the loss of a source of self-esteem and gratification (such as stepping down from a prestigious position or health problems).

\section{Impulse-Control Disorders}

These include hostile outbursts out of proportion to the provocation. A faculty member may shout at students or throw papers or other objects. Impulse control problems also may be caused by brain trauma.

\section{Substance-Related Disorders}

These disorders are generally characterized by physical evidence of drug use, erratic and unreliable behavior, flimsy excuses, and disheveled appearance. Early signs may include missing classes, failure to remember conversations or to show up for scheduled obligations, and increasingly unconvincing excuses. These symptoms may alternatively signal depression or dementias such as Alzheimer's disease. Coming to class hung over 
or under the influence of psychoactive substances may indicate a deteriorating situation or a crisis.

\section{Schizophrenia}

Schizophrenia is characterized by the presence of odd or unusual symptoms such as hallucinations, delusions, paranoia, and bizarre behaviors or by the absence of appropriate emotional reactions, withdrawal from social contact, loss of motivation, and failure to maintain personal hygiene. A faculty member with schizophrenia may be disorganized and difficult to follow in lecture or conversation. In particular, he or she may not be connecting explanations from one concept to the next, or they may be extremely obscure. The individual may have difficulty recognizing and responding to others' emotional states, may comment on experiences that seem to have no basis in reality, or may withdraw from people entirely. Symptoms may worsen during stressful periods of the semester or at times of change and transition.

\section{Dementias}

A dementia such as Alzheimer's disease is usually first noticeable due to increasing forgetfulness, particularly for recent memories. The individuals may react to forgetting with anger or denial. In class, these individuals may repeat themselves, forget to complete tasks, or lose student work. High levels of structure and stability will help those with dementia maintain their functioning, but changes in the environment are difficult for them to manage. Some organic brain disorders show similar behavioral patterns.

\section{Brain Trauma}

These traumas, often caused by strokes or accidents, can present very differently depending on the location of the damage. Common problems include poor impulse control, shortened attention span, and behavioral inconsistencies. Blackouts and abrupt changes in handwriting or other motor skills, particularly on only one side of the body, may indicate stroke. The individual may experience depression as a side effect of the damaged brain function or as a result of awareness of the loss of functioning. Brain trauma can be particularly difficult to manage in an academic environment since typical academic work requires high-level cognitive processing that even mild impairment can disrupt. Faculty may show distractibility, angry outbursts, inappropriate sexual behaviors not present prior to the trauma, 
or a lack of efficiency. Abilities may fluctuate noticeably, with one stack of papers completed correctly, while the other remains undone. Apparently stubborn or uncooperative behaviors may reflect difficulty handling change or the need for a simplified environment.

\section{Developmental Disorders}

This category includes learning disabilities, attention deficit/hyperactivity disorder (ADHD), and Asperger's syndrome.

Faculty with learning disabilities have an area of academic functioning that is significantly below their other capacities. An instructor with a learning disability in math may resist numerical grading schemes, and one with a written language disability may avoid assigning papers or serving on committees that require intensive reading and writing. An instructor with ADHD may have great difficulty organizing or finishing work, grading papers, or monitoring students. They may seem to daydream at inappropriate times.

Those with Asperger's syndrome have difficulty interpreting others' behaviors, especially in emotional situations. Many have a narrow but intense intellectual focus that lends itself to specialization in highly technical fields. Individuals with Asperger's may avoid eye contact, have difficulty with conversational exchanges (tending to dominate the conversation), and trouble filtering comments. They may be highly sensitive to sensory stimuli (light, sound, touch) and generally are rule bound. These individuals may need extensive coaching to understand the emotional communications in classroom discussions and engage in long classroom monologues. They may irritate colleagues with their rule-bound, rigid, and pedantic style.

This brief summary of mental health disorders and their possible ramifications is not meant to be exhaustive. Consider an anonymous consultation with a mental health professional to gain additional information specific to an individual case.

If there is reason to believe that a faculty member's job difficulty has a significant mental health component, what is the next step?

\section{Faculty Mental Health and the Role of the Faculty Developer}

When faculty mental health issues begin to affect the campus environment, there are several important roles that faculty developers may be called on to perform. These include educating faculty and other members of the campus community about the potential impact of mental health 
issues on teaching and learning; recognizing instances when mental health issues may be affecting the learning environment and helping to develop plans to cope with those instances; and consulting with appropriate campus offices to make sure that policies and procedures support both the impaired faculty and stakeholders such as colleagues and students.

\section{Prevention and Education}

There are several steps faculty developers can take to build healthy campus awareness of mental health situations among faculty, staff, and students. These are particularly useful for prevention and education:

- Develop policies and procedures before there is a crisis. Many campuses have no clear guidelines for handling a mental health emergency. Faculty developers may be in the best position to bring together human resources, the disability services officer, faculty affairs, counseling staff, legal counsel, and the campus police to develop policies and working relationships.

- Develop or locate resources that can be sent out when a trauma occurs-for example, "Tragedy in the College Classroom" (www. wku.edu/teaching/booklets/tragedy.htm), "Teaching and Learning in a Time of Crisis" (www.wku.edu/teaching/booklets/crisis.html), or "Stressed for Success!" (www.wku.edu/teaching/booklets/stress. $\mathrm{htm})$. Although ostensibly these materials are for faculty who are dealing with problem students, they can also inform and support faculty who struggle with mental health issues. Similarly, holding a seminar for faculty on safety in the classroom or student mental health disabilities can serve a dual function.

- Identify stressful points during the semester that may be particularly difficult for faculty with mental health issues and provide programming or other support open to all faculty, such as seminars on coping with student complaints right before midterms. Career transition programming and general stress management sessions also can be helpful.

\section{When Problems Occur}

Faculty developers may become aware of colleagues' mental health issues in several ways. Classroom problems can be an early manifestation of mental health issues and result in referral to the faculty developer. Or the faculty member may self-refer as a way to cope without acknowledging 
mental health concerns. Even if classroom problems have not emerged, the faculty developer may suspect mental health issues during routine interactions with the person or through grapevine comments from students or colleagues. Finally, faculty members may self-disclose mental health problems during consultations. Faculty members may trust the faculty developer more than their departmental colleagues, chairpersons, or deans since developers likely have no formal evaluative role. In addition, the typical confidentiality of the developer-faculty relationship can increase faculty willingness to self-disclose.

Given the likelihood of encountering faculty who are experiencing mental health issues, advance thought about if, when, and how to intervene is wise. What are the boundaries of practice for faculty developers who suspect mental health issues? What steps should faculty developers consider taking to best help everyone involved?

\section{Establishing Boundaries and the Limits of Confidentiality}

It is vitally important to understand the boundaries of the faculty developer role. Most faculty developers are not mental health professionals, and those who are cannot function ethically as therapists or psychodiagnostic experts with colleagues. We are educational experts. Unlike therapists or clergy, our confidentiality claims have no legal basis. Describing the limits of confidentiality can help both faculty and faculty developers understand the boundaries of their relationship. (See "Discussing Confidentiality in Faculty Development Settings" for sample language for a confidentiality discussion.)

\section{Understanding the Americans with Disabilities Act}

Faculty developers who are working in the United States should review the policies and procedures in place at their institution for compliance with the Americans with Disabilities Act (ADA) before proceeding. The ADA exists to prevent discrimination against disabled individuals in hiring and job performance, and many mental health disorders can be covered under ADA. Having a general understanding of ADA will help protect all parties involved.

If a faculty member has an eligible mental health disability and can perform essential job functions, then ADA requires the university to accommodate the disability unless the accommodation causes an undue hardship to the employer or the employee's behavior creates a 


\section{Discussing Confidentiality in Faculty Development Settings}

Whether and when to address confidentiality issues is a risk management question for faculty developers. If someone wants to know about getting funding or how to get teams to function better, it's probably not necessary. However, if the consultation is likely to be sensitive (for example, if the individual is upset because of poor course evaluations or referred by the department head), consider discussing the limits of the relationship between faculty member and faculty developer verbally or in writing. What follows could be used to create a verbal script or a written document. If you prefer a verbal discussion, document when the conversation occurred and what was said. With either format, make sure that the faculty member's questions and concerns are discussed. Here is a sample script:

Before we get started, I want to briefly discuss confidentiality with you so you understand the conditions under which we operate and so you can choose what to say and how much. Unlike a therapist or clergy, in this setting, we don't have any legal protections. So far, the administration has respected the limits when I say to them that I don't share information about our consultations. So we have some reasonable expectation of confidentiality based on past history. However, there are some situations in which confidentiality could be broken. The most important situation is if you say you are going to hurt yourself or someone else. In that case, I would work with you to keep everyone safe, and that could include talking with other responsible parties. The other condition in which confidentiality cannot be upheld is if I get a properly worded court order to release documents. This could happen if there were some personnel action, for example, if you sued the university.

In some states, a court order has to be properly worded (that is, setting out specific dates and naming the specific types of documents). Your situation may be different, however, so you should check with legal counsel to determine relevant laws.

When discussing confidentiality issues, strive for calm and reassuring body language, and be alert to signs of discomfort. Don't treat the situation as a joke, but help the faculty member understand that this is a necessary procedure for his or her protection. If the faculty member cannot work under these circumstances, offer to end the session and suggest options, such as a trusted friend or a professional. 
direct threat to themselves or others. The ADA can support a faculty member who needs reasonable adjustments but is having trouble getting administrative cooperation. To claim ADA protection, faculty must disclose their disability to the university. While they may choose not to disclose their status for valid reasons, including fear of stigmatization and loss of privacy, they should be aware of what they are giving up in making that choice.

If a faculty member does not disclose a disability but the faculty developer suspects one is causing job-related problems, it is important to be cautious about labeling the faculty member. Suggesting to a faculty member that he or she has bipolar disorder or PTSD would be considered labeling and could open the faculty developer and the university to discrimination complaints and litigation. Taking a descriptive, behaviorally focused approach is more useful and does not carry this risk.

Lee and Ruger (2003) provide an excellent overview of ADA issues in university settings. Always discuss the specific policies and procedures in place at your institution with ADA personnel so you can deal effectively with any at-risk faculty.

\section{Assessing the Situation and Determining Dangerousness}

In any faculty consultation, evaluation comes first. Those who are working with psychologically impaired faculty should consider the following specific questions to address, including the potential danger of the situation and the appropriate level of intervention:

1. Ascertain the faculty member's behaviors and behavioral patterns as concretely as possible. When is the situation occurring? At the start, middle, or end of class? At meetings? With whom is the problem behavior occurring? Students only? Colleagues only? Everyone all the time? What might be triggering or encouraging the behavior?

2. How intense is the behavior? Who is bothered by it? How upset is the person? This may be hard to ascertain if the faculty member is unconcerned about or unaware of the impact he or she has on others.

3. Is there any danger to students, to colleagues, or to the faculty member himself or herself? This is an anxiety-provoking possibility for many faculty developers. If the assessment process suggests possible danger, these are the steps that should be taken:

- Prepare for the possibility. Talk to appropriate campus officials to decide on a protocol before action is required. This conversation 
will likely include participation by the university legal counsel. Also consider involving the institution's employee assistance program, campus mental health professionals, the human resource department, supervisors, or the campus or community police in formulating a plan. This process will also educate you as to how best to work with these individuals if a problem arises, and when to refer them.

- If a faculty member appears to be a potential threat to self or others, do not avoid the issue. Calm, nonjudgmental honesty is the best route. Clearly state the behaviors or comments that are causing concern and encourage the individual to talk-for example, "I'm really worried about you. You seem so down when we talk, and your comments about not being around next semester concern me. I'm worried that you are thinking about hurting yourself. Are you?" With potentially suicidal individuals, a rough estimate of lethality is the level of detailed planning. An individual who vaguely refers to "not being around" is less likely to cause self-harm than someone who has purchased a gun and ammunition. Although both individuals are at risk, immediate steps should be taken to ensure the safety of the second individual such as taking him or her to the hospital or arranging for a family member or professional to do so. A person who says, "I'm so mad at that guy," is of less concern than one who admits to stalking or has planned other threatening behaviors. If the level of concern is low, try to refer the person for treatment. Empathetically repeat what he or she has said about the distress, and reinforce the idea that seeking expert advice for problems is a wise course that can help relieve personal distress.

- If the person does not seek treatment or you are concerned about possible dangerous behavior, it may be time to reach out to other campus resources. One way to do this is to meet jointly with the department chairperson, dean, or other appropriate supervisor; the faculty member; and a counselor if possible. Ideally the faculty developer will be present at this meeting because people are known to change their statements in the presence of others. If the faculty member alters or denies earlier statements, the faculty developer can repeat nondefensively what was said and describe the behavioral indicators that triggered the meeting. Typically those who are in distress are appreciative when someone notices and reaches out with respect. Sometimes the faculty member may 
become angry or alienated, but at this point, safety has to be the main concern and justification for action.

- In rare situations there may be an urgent and strongly credible threat of danger-for example, if the person has a weapon with him or her. In this case, contacting the police and protecting yourself and others without escalating the emotional situation is the priority.

\section{Giving Feedback and Cocreating an Action Plan}

Once the faculty developer has assessed the situation and determined that dangerous behavior is not an issue, the faculty member can benefit from feedback that focuses on specific, observable behaviors that are having a negative impact in the workplace-for example, "I noticed in the classroom that when a student asked a question, you answered it, but your tone of voice seemed stern to me, and you then commented about laziness. How do you think the students responded?" Stay away from "you" comments that are based on personality judgments, such as, "You're rude to students." Describing problem behaviors and discussing how to change either the behaviors or the situation allows the faculty developer to avoid labeling while at the same time recognizing and addressing the problem. A videotape of a class session may provide the most objective feedback, but may be difficult for the faculty member to view. Once the issues of concern have been jointly identified and accepted, the discussion can move to possible interventions. Whether or not the individual has acknowledged the presence of a disorder, identifying specific behaviors that are problematic for the person's success on the job can lead to productive discussions about how to change those behaviors. What would be an acceptable outcome for this situation? Is it realistic? Does the faculty member also perceive this outcome as acceptable?

So far, the approach outlined here is common to many consultations. However, several issues are more likely to arise with an underlying mental health component to a problem:

- The individual may request a referral for psychological help. Being prepared to make such referrals can reassure the faculty member that others do not find their situation unusually troubling. Talk with the campus employee assistance program, counseling center, or other mental health professionals to obtain local referral options. 
- The individual may say he or she will make a change and then does not or cannot. Now the discussion shifts to what is preventing the faculty member from making productive changes. This conversation may well lead to acknowledgment of deeper issues that the faculty member needs to address, perhaps in treatment. Another outcome might be recognition that the job requirements are too much for the faculty member to handle at this time. The faculty developer can help plan a coping strategy-for example, requesting a temporary leave or course reduction, finding another type of position, or requesting ADA-based accommodations.

- The individual may show dramatic fluctuations in behavior or signs of deterioration, increased distress, or potential threat to self or others. At this point, it may be beyond the faculty developer's role to continue to work with the individual. Recognizing the downhill trend, stepping aside from the situation, and making appropriate referrals may be the most effective steps.

\section{Keeping Appropriate Records}

Documenting the discussions and decisions of a faculty consultation is good practice in any case, but documentation is particularly important when dealing with the sensitive situations that can arise when mental health issues are involved. Following these guidelines will result in accurate, helpful, and legally sound records:

- Record and date notes on the same day the interaction occurred. Records that were made days or weeks later are less reliable and less useful if a situation does become litigious.

- Describe observable behaviors, actions, and comments, and avoid commentary. If someone cried, note that but do not label the person as "depressed." If someone says he has PTSD, write, "John said he had PTSD," rather than, "John has PTSD," so it is clear who is making this attribution.

- Do not include information that is not relevant to the matter at hand. Always write as if these notes might end up on the Internet or in a court of law. Keep personal opinions private.

- Document all recommendations. This is particularly important if it becomes necessary to demonstrate that appropriate actions were taken. 
- If there is a potential risk of danger to anyone, record the reasons for believing this, stressing the behaviors and statements that led to this conclusion, and describe the preventive steps that were taken-for example, "John stated that he has a gun at home and sometimes loads it. I walked him to the counseling center."

- Reread your notes. Have you said just enough to convey what happened objectively but not elaborated beyond that standard? If so, then sign or initial them directly below the last sentence to document their authenticity.

Working with psychologically impaired faculty is something that faculty developers are already doing, perhaps without realizing it. By becoming aware of the signs and symptoms of distress, we have the opportunity to intervene and refer in meaningful ways that will result in faculty getting the support they need, and students getting the quality educational experiences they expect.

\section{REFERENCES}

Abouserie, R. (1996). Stress, coping strategies and job satisfaction in university academic staff. Educational Psychology, 16(1), 49-56. doi:10.1080/0144341960160104

American Psychiatric Association. (1994). Diagnostic and statistical manual of mental disorders (4th ed.). Washington, DC: Author.

Blix, A. G., Cruise, R. J., Mitchell, B. M., \& Blix, G. G. (1994). Occupational stress among university teachers. Educational Research, 36(2), 157-169.

Boston University, Center for Psychiatric Rehabilitation. (n.d.). How does mental illness interfere with work performance? Retrieved from www.bu.edu/ cpr/reasaccom/employ-func.html

Dua, J. K. (1994). Job stressors and their effects on physical health, emotional health, and job satisfaction in a university. Journal of Educational Administration, 32(1), 59-78.

Dunn, J. C., Whelton, W. J., \& Sharpe, D. (2006). Maladaptive perfectionism, hassles, coping, and psychological distress in university professors. Journal of Counseling Psychology, 53(4), 511-523.

Gillespie, N. A., Walsh, M., Winefield, A. H., Dua, J., \& Stough, C. (2001). Occupational stress in universities: Staff perceptions of the causes, consequences and moderators of stress. Work and Stress, 15(1), 53-72. doi:10.1080/02678370117944

Hogan, J. M., Carlson, J. G., \& Dua, J. (2002). Stressors and stress reactions among university personnel. International Journal of Stress Management, 9(4), 289-310. doi:10.1023/A:1019982316327 
Kinman, G. (2001). Pressure points: A review of research on stressors and strains in UK academics. Educational Psychology, 21(4), 473-492. doi: $10.1080 / 01443410120090849$

Lacey, J. (2005). Prevalence and severity of mental illness in the United States [Press release]. Retrieved from www.eurekalert.org/pub_releases/2005-06/ jaaj-pas060205.php

Lee, B. A., \& Ruger, P. R. (2003). Accommodating faculty and staff with psychiatric disabilities. Washington, DC: National Association of College and University Attorneys.

Machell, D. F. (1988). A discourse on professorial melancholia. Retrieved from ERIC database. (ED304063)

Ruark, J. (2010, February 16). In academe, mental health issues are hard to recognize and hard to treat. Chronicle of Higher Education. Retrieved from http://chronicle.com/article/In-Academe-Mental-Health-I/64246/

Schwebel, D. (2009). Impaired faculty: Helping academics who are suffering from serious mental illness. Academic Leadership: The Online Journal, 7(2). Retrieved from www.academicleadership.org/article/impairedfaculty-helping-academics-who-are-suffering-from-serious-mental-illness

Winefield, A. H. (2000). Stress in academe: Some recent research findings. In D. Kenny, J. Carlson, F. McGuigan, \& J. Sheppard (Eds.), Stress and bealth: Research and clinical applications (pp. 437-446). Amsterdam, Netherlands: Harwood Academic.

Winefield, A. H., Gillespie, N., Stough, C., Dua, J., Hapuarachchi, J., \& Boyd, C. (2003). Occupational stress in Australian university staff: Results from a national survey. International Journal of Stress Management, 10(1), 51-63. doi:10.1037/1072-5245.10.1.51

Winefield, A. H., \& Jarrett, R. J. (2001). Occupational stress in university staff. International Journal of Stress Management, 8(4), 285-298. 